\title{
Training perceptions, engagement and performance: comparing work engagement and personal role engagement
}

\author{
Luke Fletcher
}

University of Brighton, Brighton, UK

\begin{abstract}
The purpose of this study was to compare two engagement constructs (work engagement and personal role engagement) with regards to their relationship with training perceptions and work role performance behaviours. It was hypothesised that personal role engagement would show incremental validity above that of work engagement at predicting work role performance behaviours and be a stronger mediator of the relationships between training perceptions and such behaviours. Questionnaire data was gathered from 304 full-time working adults in the UK. As predicted, personal role engagement was found to explain additional variance above that of work engagement for task proficiency, task adaptability, and task proactivity behaviours. Moreover, personal role engagement was a stronger mediator of the relationship between training perceptions and task proficiency as well as between training perceptions and task adaptability. Both work engagement and personal role engagement mediated the relationship between training perceptions and task proactivity to a similar degree. The findings suggest that personal role engagement has better practical utility to the HRD domain than work engagement, and indicates that future research may benefit from adopting the personal role engagement construct.
\end{abstract}

Keywords training and development; work engagement; personal role engagement; performance

Correspondence should be addressed to Luke Fletcher, Brighton Business School, University of Brighton, Mithras House, Lewes Road, Brighton, UK, BN2 4AT. 1.fletcher2@ brighton.ac.uk This is an accepted manuscript of an article published online in Human Resource Development International in July 2015. It is available from http://www.tandfonline.com/doi/full/10.1080/13678868.2015.1067855 


\section{Training perceptions, engagement and performance: comparing work engagement and personal role engagement}

\section{Introduction}

Although evidence within the HRD domain has started to demonstrate that engagement is beneficial for individual performance (Rurkkhum and Bartlett 2012) and is an important psychological experience that connects HRD practices with employee outcomes (Shuck et al. 2014), a number of different engagement constructs have been utilised. Despite most engagement research claiming to represent a similar activated and positive psychological state, there remains the issue that there is no single universally accepted and utilised engagement construct (Wefald et al. 2012). The construct being utilised is important as it should capture this particular state and not other psychological phenomenon such as flow or involvement (Little and Little 2006). In consequence, a growing number of scholars are concerned that without focused empirical examination of these constructs, the potential value of engagement, as a unique psychological construct, will be lost (Cole et al. 2012). This is of particular relevance within the HRD field as there may be subtle, yet important differences in the significance and power of different engagement constructs to predicting job performance as well as for mediating relationships between HRD practices and performance. Without understanding this issue the robustness and validity of engagement research within the HRD domain may be variable and contestable. Furthermore, given that HRD practitioners are responsible for monitoring engagement levels and designing interventions to improve engagement (Shuck and Rocco 2014), insights from such research may not provide clear and precise recommendations.

The two most dominant and widely utilised constructs of engagement applied to HRD research are work engagement (Schaufeli et al. 2002) and personal role engagement 
(Kahn 1990). Despite representing similar multidimensional and higher-order attitudinal constructs, the two conceptually differ in fundamental ways (Shuck 2011), which therefore affect the measurement of these constructs and potentially the relationship they have with HRD practices as well as with performance. Given that prior studies (Cole et al. 2012; Wefald et al. 2011) reveal that these engagement constructs show differences in their discriminant and predictive validity this is an important area to research. No studies have compared work engagement and personal role engagement in this way within the context of HRD. Identifying which construct is more empirically useful to apply to the HRD domain will help researchers focus on developing a strong, consistent and clear evidence base that can provide organisations with precise ways to measure, evaluate and improve engagement through HRD practices. This current study seeks to fill this gap by comparing and contrasting personal role engagement and work engagement as a) predictors of work performance, and b) mediators the relationship between training (as a core HRD practice) and work performance.

\section{Literature review and hypothesis development}

\section{Personal role engagement and its link with performance}

Personal role engagement was first conceptualised by Kahn (1990), who sought to develop a new approach to work motivation by undertaking an inductive ethnographic study within a summer camp for adolescents and an architecture firm. From this study, he defined engagement as the "harnessing of organization members selves to their work roles" (Kahn 1990, 694), and described it as the simultaneous expression of various facets of one's preferred self at work. These facets are connected to, and focused on, the work role: the emotional dimension of the self that reflects an energising form of positive affect; a cognitive dimension of the self that signifies a high level of intellectual activity that goes beyond the basic fulfilment of core duties; and a social dimension of the self that enables 
the individual to relate and connect with the wider work context (Soane et al., 2013). Although the emotional and cognitive dimensions exist in other operationalisations of personal role engagement (May, Gilson, and Harter 2004; Rich, LePine, and Crawford 2010), these others focus on a physical or behavioural dimension (in the form of devoting energy and effort to the job role) rather than a social dimension. Kahn (1990), and indeed others (e.g., Parker and Griffin 2011), make the distinction between the experience of engagement and the behavioural consequences of such engagement, and recently Kahn and Heaphy (2014) highlight the importance of social connectedness in the experience of engagement. Thus, social engagement may be an integral feature of 'being engaged', whereas behavioural or physical engagement may constitute an outcome rather than a dimension of engagement.

Inherent in the conceptualisation of personal role engagement is the notion that engagement is connected with high quality job performance. Personal role engagement allows individuals to demonstrate 'authenticity', i.e. "one's thoughts, feelings and beliefs are accessible within the context of role performances" (Kahn 1992, 322), thus the experience is psychological, yet the consequences are behavioural. When a person is engaged their preferred self is expressed and employed in the performance of their work role (Kahn, 1990). Empirical studies have demonstrated that the higher the level of a person's personal role engagement, the greater their performance is in terms of in-role (e.g., task performance - Rich et al. 2010) and extra-role (e.g., citizenship behaviours Alfes et al. 2012; innovation/creativity- Alfes et al. 2013; knowledge sharing - Chen, Zhang, and Vogel 2011) work behaviours. These relationships range from $r=.31$ to $r=$ .46 , and from regression co-efficients of $\beta=.25$ to $\beta=.53$. 


\section{Work engagement and its link with performance}

Work engagement was developed through a deductive and quantitative approach that focused on positioning it as the positive anti-thesis of job burnout. Consequently, it was found that although the two were highly related, engagement represented an independent construct that was not the polar opposite of burnout (Schaufeli et al. 2002). Work engagement is defined as "a positive, fulfilling work-related state of mind...that is not focused on any particular object, event, individual, or behavior" (Schaufeli et al. 2002, 74). It is focused on the broad scope of work activities and manifests as a higher-order attitudinal state that comprises three dimensions: feeling energised and vigorous (Vigor); feeling proud of and dedicated to one's work (Dedication), and feeling absorbed and immersed in one's work (Absorption). Thus, work engagement represents a sense of energy and identification with work activities (Schaufeli and Bakker 2010). However, this construct of engagement has been questioned as there is evidence to show that work engagement "overlaps to such an extent with job burnout... that it effectively taps an existing construct under a new label" (Cole et al. 2012, 1573).

Despite this, work engagement is theorised to be related to job performance because it signifies an energetic and involved motivational state that directs an individual's efforts towards the completion of work tasks and activities (Parker and Griffin 2011). There are a growing number of studies that show a positive relationship between work engagement and work role behaviours, both in-role (e.g., Gorgievski, Bakker, and Schaufeli 2010) and extra-role (e.g., citizenship behaviours -Sulea et al. 2012; innovation/creativity- Bakker and Xanthopoulou 2013; adaptability - Barnes and Collier 2013; personal initiative/proactivity - Den Hartog and Belschak 2012). These relationships range from $r=.30$ to $r=.51$, and from regression co-efficients of $\beta=.23$ to $\beta=.42$. 


\section{Comparing personal role engagement and work engagement constructs}

Table 1 summarises the conceptual foundations of the two engagement constructs. Drawing on this, I argue that personal role engagement represents a fuller, deeper, and more immersive concept than work engagement. Crucially, personal role engagement differs from work engagement because it attempts to capture the authentic and complete expression of one's preferred self to one's work role performance rather than just the employment of energies into work activities (Kahn and Heaphy 2014; Schaufeli and Bakker 2010). This then allows for full and active work role performance as key aspects of the self are simultaneously expressed in a connected way within the work role (Rich et al. 2010), and so "highlights not only the connection between engagement and work role performance...but also the notion of personal agency or agentic self" (Cole et al. 2012, 1576). This psychological involvement with work is more holistic, synergistic and distinct than the narrower work engagement construct that views it as being "a high level of energy and strong identification with one's work" (Schaufeli and Bakker 2010, 13). Work engagement is focused on the attitudinal connection that an individual has with their work activities rather than the expression of the self in one's work role, and so is more about a 'state of mind' whilst at work rather than a 'state of self-expression' (Kahn and Heaphy 2014; Schaufeli et al. 2002). This can be seen when comparing the different measurements of the two constructs.

Although there are similarities between the Soane et al's (2013) and Schaufeli et al's (2002) measures, notably the items reflecting the affective engagement and dedication dimensions, there are fundamental differences. Soane et al (2013) focus on intellectual engagement in the form of attention and focus whereas Schaufeli et al (2002) focus on absorption and cognitive intensity. Given that attention and absorption are related, yet different features of cognitive activation, with the latter connoting a core element of the 
flow experience (Csíkszentmihályi 1991; Rothbard 2001), these two dimensions may elicit different behavioural responses. Rothbard $(2001,678)$ argues that attention may represent "an invisible, material resource that a person can allocate in multiple ways...[whereas absorption] is linked to intrinsically motivated interest", and so it may be that attention facilitates performance more broadly and fully as absorption is only directed towards performance in personally interesting tasks. Another fundamental difference is that Soane et al (2013) focus on the perceived social connection between the individual and their work environment in the form of social engagement whereas Schaufeli et al (2002) focus on energy and mental resilience in the form of vigor. Social engagement may be associated with contextual performance given the relational nature of citizenship and prosocial behaviours (Borman and Motowidlo 1997) whereas vigor may be more narrowly focused task performance due to its focus on energy and work activities (Schaufeli and Bakker 2010).

Based on the above arguments, this paper proposes that personal work engagement will exhibit a stronger relationship with a range of work role behaviours than work engagement, and will contribute more to their prediction (in terms of explained variance). Initial evidence shows that personal role engagement explained $6 \%$ additional variance, above that of work engagement, in task performance and $1 \%$ in citizenship behaviour (Soane et al. 2013).

Hypothesis 1: Personal role engagement will demonstrate incremental validity above that of work engagement in relation to predicting work role behaviours Hypothesis 2: Personal role engagement will contribute more to the prediction (in terms of explained variance) of work role behaviours than work engagement 


\section{The mediating role of engagement in the relationship between training perceptions and}

\section{performance}

Training is a specific HRD practice that facilitates performance because it develops the technical and personal skills needed to perform a job effectively (Aguinis and Kraiger 2009). However, employees will perceive these practices in different ways according to their prior experiences of training and their thoughts about why management are enacting them (Nishii, Lepak, and Schneider 2008). It is these individual perceptions that have the strongest influence on employee attitudes and behaviours (Guest 2002). Indeed, evidence shows that training perceptions are related to individual productivity (Paul and Anantharaman 2003). Moreover, the link between training perceptions and work role performance is likely to be indirect because it activates motivational processes that direct energies towards goal attainment (Dysvik and Kuvass 2008). As engagement is seen as an active, motivational construct (Parker and Griffin 2011), it is therefore argued that positive perceptions of training will lead to higher levels of performance via the experience of engagement. Studies show that training perceptions are directly linked with engagement levels (Salanova, Agut, and Peiró 2005), and perceptions of HR practices, including training, are indirectly related to performance via engagement (Alfes et al. 2012).

However, it is not known whether work and personal role engagement may have similar or different mediating effects on the relationship between training perceptions and work role performance. This paper proposes that personal role engagement will be a stronger mediator than work engagement because personal role engagement does not just direct energy and dedication into completing tasks but also deepens the meaning and sense of fulfilment of all aspects of the work role (May et al. 2004). This facilities high quality performance because it meets critical psychological conditions that parallel a relational psychological contract; namely meaningfulness, availability, and safety (Kahn 1990). 
Meaningfulness connotes feeling that one's work role is 'worthwhile, useful and valuable', and derives primarily from motivational job design, positive role status and identity, and rewarding social interactions (May et al. 2004). Availability signifies that there are enough perceived resources available to engage, and is depleted when there are excessive and competing demands, insecurity about one's role and place in the organisation, and where outside lives interference with one's work (Kahn 1990). Lastly, safety represents the perception that one can express one's thoughts and feelings without fear of negative consequences. This occurs when one is able to trust others and be open at work, and is derived from interpersonal relationships, managerial behaviours, and workplace norms (Kahn and Heaphy 2014). Training could be seen to fulfil these psychological conditions. First, training provides employees with knowledge and understanding that makes work more meaningful (Rana 2015). Second, training develops important personal resources that enable employees to feel psychologically able to sustain healthy levels of engagement (Gruman and Saks 2011). Lastly, training can foster a respectful and psychologically safe environment through raising awareness of diversity, conflict and incivility issues (Reio and Sanders-Reio 2011). Thus, personal role engagement acts as a contextually embedded psychological mechanism that connects training with the full expression of the self in one's work role (Kahn 1990).

Work engagement, in contrast, focuses on the ability of engaged individuals to gain and mobilise job resources in their work environment and personal resources so that performance can be enhanced (Bakker and Demerouti 2008), and as such views training as a functional organisational resource that primarily acts to build self-efficacy, which in turn can lead to engagement and performance (Schaufeli and Salanova 2008). This resourcebased perspective has been criticised for reducing the role of engagement as "a transactional commodity that occurs because someone else dispenses resources" 
(Bargagliotti 2011, 1416), and as representing "a dangerously simplistic view of work relations" (Purcell 2014, 242). Thus, it may be that work engagement is a weaker mediator than personal role engagement of the relationship between training perceptions and work performance due to focusing on the economic transaction between the organisation and the employee in terms of resources and effort. Moreover, work engagement theory does not consider the particular value of different forms of resources and instead views resources as a general composite factor consisting of a mixture of job design, leadership, social support, and organisational practices (Bakker and Demerouti 2008). This lack of precise understanding of the role of training and of engagement as a mediator between training and performance limits the robustness and application of work engagement theory to the HRD domain.

Hypothesis 3: Personal role engagement will mediate the relationships between training perceptions and work role behaviours to a greater degree than work engagement.

\section{Method}

\section{Sample and participants}

An online questionnaire was sent to fulltime employed workers, resident in the UK, via a market research company. The sample was generated by the market research company from a database of enrolled members of the public who receive credit points for completing surveys sent by the company. These points can be exchanged for monetary vouchers once enough have been gained. A total of 304 respondents completed the questionnaire; of which 55\% were male, $43 \%$ were degree educated or higher, and $45 \%$ had managerial responsibilities. A range of occupational groups were represented; the highest proportions being administrative/secretarial (28\%) and professional workers 
$(25 \%)$. The average age of respondents was 41.45 years $(S D=11.69)$, and the average length of tenure with the current employer was 9.96 years $(S D=8.94)$.

\section{Measures}

\section{Training perceptions}

Schmidt's (2007) four-item satisfaction with training scale was used to measure training perceptions. An example item is 'The amount of training I receive is satisfactory'. Respondents were asked to indicate how strongly they agreed/disagreed with each statement on a 5-point Likert scale (1- strongly disagree, 5- strongly agree). This scale exhibited high inter-item reliability $(\alpha=.90)$.

\section{Work engagement}

The 9-item UWES (Schaufeli and Bakker 2003) was used to measure work engagement because it has been found to be statistically more robust than the original 17 item version (Seppälä et al. 2009). Respondents were asked to rate the frequency (1-never to 5-always) to which they experienced, at work, the feeling described in each statement. Three statements referred to feelings of vigor (e.g. 'At work I am bursting with energy'), three to feelings of dedication (e.g. 'My job inspires me') and three to feelings of absorption (e.g. 'I am immersed in my work'). The UWES demonstrated high inter-item reliability as an overall measure $(\alpha=.94)$ and as its dimensions $(\alpha=.84$ to .87$)$.

\section{Personal role engagement}

The 9-item ISA scale (Soane et al. 2013) was used to measure personal role engagement as the holistic expression of one's preferred self at work (Kahn 1990). It was developed directly from Kahn's theorising in that the measure is based on the rationale that three elements of a work role enable engagement to occur: a focused role that helps with the alignment of self and role, activation that triggers affective and cognitive responses to the role, and positive affect that broadens thoughts and actions related to the 
role. The ISA scale captures the key aspects of engagement in terms of intellectual engagement (3 items e.g. 'I focus hard on my work'), social engagement ( 3 items e.g. 'I share the same work attitudes as my colleagues') and affective engagement ( 3 items e.g. 'I am enthusiastic in my work'). Respondents are asked to indicate how strongly they agree/disagree with each statement on a 5-point Likert scale (1- strongly disagree, 5strongly agree). It has demonstrated to be reliable and valid with existing studies showing Cronbach alpha scores of between .81 and .88 , and discriminant validity against perceived employee voice, HRM practices, line manager relationships/behaviours, and task/contextual performance (Alfes et al. 2013; Rees et al. 2013; Soane et al. 2013). In this study, the ISA scale exhibited high inter-item reliability as an overall measure $(\alpha=.91)$ and as its constituent facets $(\alpha=.91$ to .94$)$.

Work role behaviours

Griffin, Neal and Parker (2007) provide a useful and encompassing framework to examine work role behaviours. They integrated various strands of performance literature to develop and test three distinct forms of positive work role performance behaviours: proficiency, adaptability, and proactivity. For this study, the focus will be on individual task performance, and so Griffin et al's (2007) three-item task proficiency scale (e.g. 'I carried out the core parts of my job well'), three-item task adaptability scale (e.g. 'I adapted well to changes in core tasks') and three-item proactivity scale ('I initiated better ways of doing my core tasks') were used. Respondents were instructed to rate how often (1- not at all to 5-a great deal) they enacted each behaviour at work in the previous month. These scales demonstrated high reliabilities ( $\alpha=.95, .82, .94$; respectively).

\section{Control variables}

As a range of different types of workers were surveyed from various organisations in the UK, it was deemed appropriate to control for the following characteristics: gender 
$(0=$ male, $1=$ female $)$, age (in years), tenure (in years), and management responsibility $(0-$ no, 1- yes). These characteristics are typically controlled for when examining the antecedents of work behaviours because they may have some degree of association with these antecedents and/or outcomes (e.g., Chen et al. 2011).

\section{Results}

\section{Descriptive statistics}

Means, standard deviations and correlations between the variables are given in Table 2. Work engagement and personal role engagement were positively correlated with task proficiency, task adaptability, and task proactivity.

\section{INSERT TABLE 2 HERE}

\section{Measurement models}

Due to the data being collected from a single source only, there is a need to consider common method bias and discriminant validity (Podsakoff et al. 2003). Confirmatory factor analyses (CFAs) were conducted to verify the underlying theoretical constructs and to control for the influence of common method bias. The likelihood ratio $\chi^{2}$ and degrees of freedom were calculated. The following fit indices were also used to determine model fit more accurately: a) Root Mean Square Error of Approximation (RMSEA; Steiger 1990) where values of .10 or below indicates a plausible fit; b) the Comparative Fit Index (CFI; Bentler 1990), where a value of .90 or above indicates a plausible fit; c) the standardized Root Mean Square Residual (SRMR; Hu and Bentler 1999) where values of .08 or below indicates a plausible fit.

First, CFAs were conducted on the two engagement constructs as they represent similar psychological concepts. The UWES and the ISA scales are thought to represent three dimensions of engagement each. Indeed the CFAs found support for the six factor structure, and this was the best fitting models compared with alternative one to five factor 
solutions (see Table 3). Further to this, the vigor (.94), dedication (.99), and absorption (.86) dimensions loaded onto the higher-order UWES factor well; and the intellectual (.62), social (.56), and affective (.95) facets loaded onto the higher-order ISA factor well. Second, the distinction between all six latent variables (i.e., training perceptions, work engagement, personal role engagement, task proficiency, task adaptability, and task proactivity) was tested. As work engagement and personal role engagement constructs were second-order factors, a form of item parcelling was used to represent these factors (i.e., factors represented by the sub-dimensions rather than the individual items). This is an acceptable way to characterise higher-order factors within CFA analyses (Martin, Malmberg and Liem 2010). The CFAs confirmed that the six factor solution was a good fit, and a better fitting solution than alternative one to five factor solutions (see Table 4).

INSERT TABLE 3 HERE

\section{INSERT TABLE 4 HERE}

\section{Tests of hypotheses}

The direct relationship between the engagement constructs and work role behaviours

Hierarchical linear regression analyses were performed to determine which variables were unique predictors of the work role behaviours. For each dependent variable, two steps were conducted. The first was a regression that included the control variables and work engagement to ascertain the variance explained by work engagement alone; the second was a regression that built from the first step and included personal role engagement in order to ascertain whether personal role engagement has incremental validity. Univariate relative importance analyses (Tonidandel and LeBreton 2011) were performed on the step 2 regression using the online RWA-WEB program (Tonidandel and LeBreton 2014). Relative importance analysis supplements traditional regression analyses by helping to understand which predictors are contributing most to the prediction of a 
criterion variable (Tonidandel and LeBreton 2011). The RWA-WEB program estimates the relative weight indices $(r w)$ for each predictor along with bootstrapped confidence intervals $(10,000$ replications using alpha of 0.05$)$, where the range should not include zero to be deemed significant.

Table 5 shows the results of these regression analyses. The results of step 1 across the behavioural outcomes show that work engagement was positively related to task proficiency $(\beta=.28, p<.001)$, task adaptability $(\beta=.33, p<.001)$, and task proactivity $(\beta$ $=.41, p<.001)$. However, when personal role engagement was added to these models (step 2) the relationships between work engagement and a) task proficiency, and b) task adaptability became non-significant. The relationship between work engagement and task proactivity remained significant, albeit reduced. In contrast, the associations between personal role engagement and the behavioural outcomes were all significant: task proficiency $(\beta=.41, p<.001)$, task adaptability $(\beta=.39, p<.001)$, and task proactivity $(\beta$ $=.19, p<.001)$. These second models (step 2) explained a significant amount of additional variance than the first models (step 1): an additional $9 \%$ in task proficiency, $8 \%$ in task adaptability, and $2 \%$ in task proactivity. Therefore, Hypothesis 1 was supported as personal role engagement demonstrated incremental validity above that of work engagement in the prediction of all three work role behaviours. Moreover, the relative weights analysis shows that personal role engagement contributed significantly more than work engagement to the prediction of task proficiency $(r w=.12$ versus .03$)$ and task adaptability $(r w=.14$ versus .05$)$, and contributed to a similar degree as work engagement to the prediction of task proactivity ( $r w=.08$ versus .10 ). Thus, Hypothesis 2 was largely supported. 
The indirect relationships between training perceptions and work role behaviours via work engagement and personal role engagement

To test for mediation, the steps outlined by Baron and Kenny (1986) were followed. Table 6 shows the results of these steps. Firstly, training perceptions were positively related to task proficiency $(\beta=.17, p<.05)$, task adaptability $(\beta=.23, p<.001)$, and task proactivity $(\beta=.24, p<.001)$. Thus, the first condition of mediation was met, i.e. that the predictor is related to the dependent variable. Secondly, training perceptions were positively related to work engagement $(\beta=.47, p<.001)$ as well as to personal role engagement $(\beta=.59, p<.001)$, thus meeting the second condition of mediation, i.e. that the predictor is related to the mediator. Thirdly, both work engagement and personal role engagement reduced (most to non-significance) the relationship between training perceptions and a) task proficiency $(\beta=.06, p>.05 ; \beta=-.12, p>.05)$, b) task adaptability $(\beta=.16, p<.05 ; \beta=.01, p>.05)$, and $\mathrm{c})$ task proactivity $(\beta=.09, p>.05 ; \beta=.05, p>.05)$. Moreover, work engagement and personal role engagement were still positively related to task proficiency $(\beta=.23, p<.001 ; \beta=.49, p<.001)$, task adaptability $(\beta=.16, p<.05 ; \beta=$ $.38, p<.001)$, and task proactivity $(\beta=.32, p<.001 ; \beta=.32, p<.001)$. This meets the third and fourth conditions of mediation, i.e. the mediator affects the dependent variable when the predictor is controlled for and reduces the relationship between the predictor and dependent variable.

To fully establish mediation, the PROCESS tool by Hayes (2014) was used. Table 7 shows the results of the mediation tests. The lower and upper bounds of the indirect effect for the relationship between training perceptions and each of three work role behaviours via a) work engagement and b) personal role engagement was greater than zero. However, the effect sizes were much larger for personal role engagement as the mediator than for work engagement as the mediator (.08 to .15 versus .19 to .29 ). This 
indicates that personal role engagement is a stronger mediator of the relationships between training perceptions and work role behaviours than work engagement, and so provides support for Hypothesis 3.

INSERT TABLE 6 HERE

INSERT TABLE 7 HERE

\section{Discussion}

Although evidence within the HRD domain has started to demonstrate that engagement is beneficial for individual performance (Rurkkhum and Bartlett 2012) and is an important psychological experience that connects HRD practices with employee outcomes (Shuck et al. 2014), there is an issue that a range of constructs are being utilised from different theoretical approaches. To clarify which approach may have the most practical utility to the HRD domain, two of the most dominant engagement constructs were compared: work engagement (Schaufeli et al. 2002) and personal role engagement (Kahn 1990). This is the first study to compare the predictive power of these two constructs on job performance and their mediating role in the relationship between HRD practice and performance.

First, the predictions that personal role engagement would be a stronger predictor of work role behaviours than work engagement were largely supported. Personal role engagement was shown to have incremental validity over work engagement for all three work role behaviours. Moreover, the relative weight analysis demonstrated that personal role engagement contributed much more to the prediction of task proficiency and task adaptability than work engagement. Both work and personal role engagement contributed similarly to the prediction of task proactivity. These findings collectively indicate that personal engagement has slightly better predictive power than work engagement with regards to performance. They add to those of Soane et al (2013) by demonstrating that 
personal role engagement is a stronger predictor than work engagement of not only task performance behaviours, but also adaptability behaviours. This study shows support for the theoretical distinction between personal role engagement as a 'state of self-expression' and work engagement as a 'state of mind' (Kahn and Heaphy 2014). This finding is important as it clarifies an important conceptual and theoretical distinction between the two constructs that has hitherto not been empirically examined. Personal role engagement seems to reflect a more holistic and synergistic engagement construct that fosters full work role performance (Kahn 1990), whereas work engagement seems to represent a narrower and more specific engagement construct that facilitates high levels of energy and identification with work tasks (Schaufeli and Bakker 2010). This is an important finding as it indicates that personal role engagement, rather than work engagement, should be applied when examining job performance. The finding that work engagement is most strongly associated with task proactivity suggests that work engagement directs energies into work activities that specifically seek to demonstrate personal initiative, whereas personal role engagement seems to direct energies into the wider scope of the work role.

Second, the study is one of the first to empirically evidence that training perceptions are linked with performance behaviours via engagement, and demonstrate that personal role engagement is a stronger mediator of these relationships than work engagement. This shows support for the argument that training provides a meaningful, safe and resourceful social context that enables the full expression of the self in one's work role performances (Gruman and Saks 2011; Rana 2015; Reio and Sanders-Reio 2011). Work engagement may focus too narrowly on the transaction of resources in exchange for effort (Bargagliotti 2011), and so may not be as theoretically comprehensive as personal role engagement theory. This study affirms recent theorising within HRD research that has focused on connecting Kahn's (1990) personal role engagement theory to 
HRD practice (e.g., Shuck and Rocco 2014), and, along with other studies have found that the measurement of work engagement is psychometrically problematic (Cole et al. 2012; Wefald et al. 2010), calls into question the utility and distinct value of work engagement to the HRD domain. In sum, this current study gives tentative support to Cole et al's (2012) arguments that engagement research should move away from adopting work engagement and towards utilising personal role engagement.

\section{Implications for future research}

The findings of this study highlight a number of important implications for future research. First, it suggests that further empirical testing of Kahn's theoretical propositions will enhance the utility of engagement research to the HRD domain. One of Kahn's core propositions concerns the role of meaningfulness, safety and availability as universal psychological conditions that, when fulfilled, connect the wider work context with the experience of engagement. In this study, it was argued that training fulfils these conditions, yet these propositions were not directly tested, and so future research should examine the relationships between various HRD practices, the psychological conditions of meaningfulness, availability and safety, and personal role engagement. This will shed light on whether meaningfulness, safety and availability are the key psychological processes that connect HRD practices with engagement. Moreover, it will provide a deeper understanding of the psychological effects of HRD practices and in doing so may provide opportunities to integrate theories in ways that contribute to a more holistic and deeper understanding. For example, Gruman and Saks (2011) suggest that Kahn's (1990) psychological conditions and Bakker and Demerouti’s (2008) job demands-resources model could be integrated to provide more comprehensive explanations.

Second, by focusing on personal role engagement future researchers will be encouraged to examine the subjective experience of engagement within particular 
organisational contexts (Kahn 1990). Considering that much research on work engagement has been 'bemoaned' for neglecting to examine such features (Jenkins and Delbridge 2013; Purcell 2014), there is ample opportunity for researchers to further explore how occupational and organisational contexts may vary in the extent to which they are engaged by different HRD practices. In doing so, a more nuanced and contextualised understanding of HRD can develop. This in turn will provide HRD practitioners with specific recommendations that are suited to their needs, and in doing so could connect with calls to further explore the individualised experience of engagement through academic and practitioner collaborations (Shuck and Rocco 2014).

Third, the study shows that further comparison of personal role engagement and work engagement may be warranted. One area to focus on is the conceptual differences between the two constructs. For example, personal role engagement and work engagement differ conceptually with regard to their 'state' properties: personal role engagement has fundamentally been viewed as a transient and focused state that fluctuates during and across workdays in response "to the momentary ebbs and flows of those days" (Kahn 1990, 693), whereas work engagement has been conceptualised as a 'persistent and pervasive' state of mind (Schaufeli et al. 2002). Future research may want to explore these temporal properties by examining the effects of engagement on performance across various time periods. These studies would also benefit from including supervisor-rated and/or objective performance indicators, such as appraisal ratings, sales data, or observational behavioural checklists. Another area to focus on is the wider theoretical and nomological net of engagement. It may be useful to examine whether personal role engagement has a wider set of antecedents and outcomes than work engagement given that this study suggests that it represents a more holistic and synergistic construct than work engagement. 
Lastly, there is an opportunity for researchers to critically examine the construct of work engagement and its specific connection with wellbeing and health. This study has shown evidence that work engagement may not be the panacea for all workplace issues there may be more powerful constructs for certain purposes, in this case for evaluating and improving HRD practices and performance interventions. Given that there is evidence to suggest that the work engagement construct may overlap with job burnout (Cole et al. 2012) and may be psychometrically flawed (Wefald et al. 2012), there is a need to critically examine the use and value of work engagement. This is not to say that work engagement is a redundant construct, but the continued assertion that it is "an independent, distinct concept...characterized by vigor, dedication, and absorption" (Schaufeli and Bakker 2010, 13) should at least be questioned and scrutinised. It might be that work engagement has a more focused and specific role given that it focuses on energy and identification with work activities so that work is enjoyable and fulfilling (Schaufeli and Bakker 2010). Therefore, research may consider focusing on the specific functional pathways that connect work engagement with intrinsically motivating work activities that enable personal initiative and proactivity.

\section{Practical implications}

Organisations wishing to increase employee performance may consider helping employees to connect with their work roles emotionally, cognitively and socially (Kahn 1990). For example, line managers could encourage employees to express their true feelings and opinions through team meetings and personal development workshops, and HRD practitioners could design workplace development programmes that tailors learning to individual work roles, promotes social relationships and connects the individual with the wider contribution and impact that their work role has within the organisation (Kahn and Heaphy 2014). This 'soft' approach may work better in some organisations than others, 
particularly those that already value employee engagement and wellbeing as goals in themselves (Jenkins and Delbridge 2013). It may be more challenging for organisations that adopt a more universally 'hard' approach to HRM and employee relations, in which performance and productivity are the primary objectives. These organisations may not want their employees to express their thoughts and feelings or to find wider meaning in their work, especially if it might cause resistance and heightened expectations of the employment relationship. HRD practitioners should be cognisant of these different contexts, and should alter their approach accordingly. In such organisations, instrumental HRD practices may be more useful to drive change. For example, providing technical training opportunities that build human capital could be utilised to enhance both performance and engagement, as this study has empirically demonstrated. Building a business case for continued investment in training and development will also be important as there will be a pressure to maintain tight managerial and economic control (Jenkins and Delbridge 2013), and evidence suggests that when employees perceive that their organisation invests in their training and development they will be more engaged (Shuck et al. 2014). However, HRD practitioners should try to include some softer forms of practice so that the balance of the employment relationship is maintained.

In order to monitor and evaluate the success of HRD interventions, 'soft' or 'hard', practitioners could use Soane et al's (2013) personal role engagement measure to assess engagement levels before and after to evaluate how the intervention has improved the psychological connection between the individual and their work role, and will give an indication of the potential impact on performance levels. By utilising this measure consistently over time, organisations will be able to monitor the relative success of different interventions and will be able use this evidence to adapt and enhance HRD practices to best suit the changing needs of their workforce. 


\section{Study limitations}

There are a few limitations of this study that should be kept in mind when considering the implications of the findings. Firstly, even though the study verified the factor structures to test for common method bias, there remains the issue of crosssectionality (Maxwell and Cole 2007). Longitudinal studies are needed to fully confirm the casual relationship between HRD practices, engagement, and performance. Another limitation is that this study used self-report measures of performance behaviours. Although self-assessed performance measures are valid ways of gaining performance information (Vance et al. 1988), they can be inflated in self-reports compared to bossratings (Heidemeier and Moser 2009), and may not always reflect objective performance (Pransky et al. 2006). To mitigate against these risks, a set of performance scales were chosen that were validated across different organisations and self-/supervisor-assessed ratings (see Griffin et al. [2007] for details). Related to this, this current study focused on one type of HRD practice; namely training. HRD includes a range of practices, such as career development and workplace learning (Shuck and Rocco 2014). A final limitation is that the sampling method utilised did not allow for the appreciation or examination of organisational, industry or societal context. It is increasingly acknowledged that neglecting to consider the impact of the wider organisational environment on research findings can limit or reduce the validity and reliability of those findings (Johns 2006). Moreover, the salience of different performance foci (e.g., individual vs team; in-role vs extra-role) is likely to vary across different industry and occupational contexts (Griffin et al. 2007).

\section{Conclusion}

To conclude, this paper found that personal role engagement was a more powerful predictor of work role behaviours than work engagement, and was a stronger mediator than work engagement of the relationships between training perceptions and work role 
behaviours. This suggests that the personal role engagement theory may be more useful when examining psychological processes that underpin the relationships between HRD practices and performance outcomes than work engagement theory. Overall, HRD research would benefit from exploring, expanding and testing the propositions made by personal role engagement theory in more depth. HRD practitioners should consider how training and development practices can be better designed to foster engagement.

\section{References}

Aguinis, H., and K. Kraiger. 2009. "Benefits of Training and Development for Individuals and Teams, Organizations, and Society.” Annual Review of Psychology, no. 60: 451-474. doi:10.1146/annurev.psych.60.110707.163505

Alfes, K., A. Shantz, C. Truss, and E.C. Soane. 2012. "The Link between Perceived Human Resource Management Practices, Engagement and Employee Behavior: A Moderated Mediation Model." The International Journal of Human Resource Management 24 (2): 330-351. doi:10.1080/09585192.2012.679950

Alfes, K., C. Truss, E.C. Soane, C. Rees, and M. Gatenby. 2013. “The Relationship between Line Manager Behavior, Perceived HRM Practices, and Individual Performance: Examining the Mediating Role of Engagement.” Human Resource Management 52 (6): 839-859. doi: 10.1002/hrm.21512

Bakker, A. B., and E. Demerouti. 2008. "Towards a Model of Work Engagement.” Career Development International 13 (3): 209-223. doi:10.1108/13620430810870476

Bakker, A. B., and D. Xanthopoulou. 2013. "Creativity and Charisma among Female Leaders: The Role of Resources and Work Engagement.” The International Journal of Human Resource Management 24 (14): 2760-2779. doi: $10.1080 / 09585192.2012 .751438$ 
Bargagliotti, L.A. 2012. "Work Engagement in Nursing: A Concept Analysis.” Journal of Advanced Nursing 68 (6): 1414-1428. doi: 10.1111/j.1365-2648.2011.05859.x

Barnes, D. C., and J.E. Collier. 2013. "Investigating Work Engagement in the Service Environment.” Journal of Services Marketing 27 (6): 485-499. doi:10.1108/JSM012012-0021

Baron, R.M., and D.A. Kenny. 1986. "The Moderator-Mediator Variable Distinction in Social Psychological Research: Conceptual, Strategic, and Statistical Considerations.” Journal of Personality and Social Psychology 51 (6): 1173-1182. doi:10.1037/00223514.51.6.1173

Bentler, P. M. 1990. “Comparative Fit Indexes in Structural Models.” Psychological Bulletin 107 (2): 238-246. doi:10.1037/0033-2909.107.2.238

Borman, W. C., and S.J. Motowidlo. 1997. "Task Performance and Contextual Performance: The Meaning for Personnel Selection Research.” Human Performance 10 (2): 99-109. doi: 10.1207/s15327043hup1002_3

Chen, Z., X. Zhang, and D. Vogel. 2011. "Exploring the Underlying Process between Conflict and Knowledge Sharing: A Work-Engagement Perspective.” Journal of Applied Social Psychology 41 (5): 1005-1033. doi:10.1111/j.1559-1816.2011. 00745.

Cole, M.S., F. Walter, A.G. Bedeian, and E.H. O'Boyle. 2012. “Job Burnout and Employee Engagement: A Meta-Analytic Examination of Construct Proliferation." Journal of Management 38 (5): 1550-1581. doi: 10.1177/0149206311415252

Csíkszentmihályi, M. 1991. Flow: The Psychology of Optimal Experience. New York: Harper Collins. 
Den Hartog, D. N., and F. D. Belschak. 2012. "Work Engagement and Machiavellianism in the Ethical Leadership Process.” Journal of Business Ethics 107 (1): 35-47. doi:10.1007/s10551012-1296-4

Dysvik, A., and B. Kuvaas. 2008. "The Relationship between Perceived Training Opportunities, Work Motivation and Employee Outcomes.” International Journal of Training and Development 12 (3): 138-157. doi:10.1111/j.14682419.2008.00301.x

Gorgievski, M. J., A. B. Bakker, and W. B. Schaufeli. 2010. "Work Engagement and Workaholism: Comparing the Self-Employed and Salaried Employees.” The Journal of Positive Psychology 5 (1): 83-96. doi: 10.1080/17439760903509606

Griffin, M. A., A. Neal, and S.K. Parker. 2007. “A New Model of Work Role Performance: Positive Behavior in Uncertain and Interdependent Contexts." Academy of Management Journal 50 (2): 327-347. doi:10.5465/AMJ.2007. 24634438

Gruman, J. A., and A.M. Saks. 2011. "Performance Management and Employee Engagement.” Human Resource Management Review 21 (2): 123-136. doi:10.1016/ j.hrmr.2010.09.004

Guest, D. E. 2002. "Human Resource Management, Corporate Performance and Employee Wellbeing: Building the Worker into HRM.” The Journal of Industrial Relations 44 (3): 335-358. doi:10.1111/1472-9296.00053

Hayes, A.F. 2014. The PROCESS Macro for SPSS and SAS. Version 2.13. [Computer Software]. Available from http://www.processmacro.org

Heidemeier, H., and K. Moser. 2009. "Self-Other Agreement in Job Performance Ratings: A Meta-Analytic Test of a Process Model.” Journal of Applied Psychology 94 (2): 353-370. doi: 10.1037/0021-9010.94.2.353 
Hu, L. T., and P.M. Bentler. 1999. "Cutoff Criteria for Fit Indexes in Covariance Structure Analysis: Conventional Criteria versus New Alternatives." Structural Equation Modeling 6 (1): 1-55. doi:10.1080/10705519909540118

Jenkins, S. and R. Delbridge. 2013. "Context Matters: Examining 'Soft' and 'Hard' Approaches to Employee Engagement in Two Workplaces." The International Journal of Human Resource Management 24 (14): 2670-2691. doi: $10.1080 / 09585192.2013 .770780$

Johns, G. 2006. “The Essential Impact of Context on Organizational Behavior.” Academy of Management Review 31 (2): 386-408. doi: 10.5465/AMR.2006.20208687

Kahn, W. A. 1990. "Psychological Conditions of Personal Engagement and Disengagement at Work." Academy of Management Journal 33 (4): 692-724. doi: $10.2307 / 256287$

Kahn, W. A. 1992. "To be Fully There: Psychological Presence at Work.” Human Relations 45 (4): 321-349. doi: 10.1177/001872679204500402

Kahn, W.A., and E.D. Heaphy. 2014. "Relational Contexts of Personal Engagement at Work.'In Employee Engagement in Theory and Practice, edited by Catherine Truss, Rick Delbridge, Kerstin Alfes, Amanda Shantz and Emma Soane, 82-96. London: Routledge.

Little, B. and P. Little. 2006. “Employee Engagement: Conceptual Issues.” Journal of Organizational Culture, Communications and Conflict 10 (1): 111-120. ISSN: 15440508

Martin, A.J., L.E. Malmberg, and G.A.D. Liem. 2010. "Multilevel Motivation and Engagement: Assessing Construct Validity across Students and Schools.” Educational and Psychological Measurement 70 (6): 973-989. doi:10.1177/0013164410378089 
Maxwell, S.E, and D.A. Cole. 2007. "Bias in Cross-Sectional Analyses of Longitudinal Mediation.” Psychological Methods 12 (1): 23-44. doi:10.1037/1082989X.12.1.23

May, D.R., R.L. Gilson, and L.M. Harter. 2004. "The Psychological Conditions of Meaningfulness, Safety and Availability and the Engagement of the Human Spirit at Work." Journal of Occupational and Organizational Psychology 77 (1): 11-37. doi:10.1348/096317904322915892

Nishii, L. H., D. P. Lepak, and B. Schneider. 2008. "Employee Attributions of the "Why" of HR Practices: Their Effects on Employee Attitudes and Behaviors, and Customer Satisfaction.” Personnel Psychology 61 (3): 503-545. doi:10.1111/j.1744-6570.2008.00121.x

Parker, S. K. and M. A. Griffin. 2011. "Understanding Active Psychological States: Embedding Engagement in a Wider Nomological Net and Closer Attention to Performance.” European Journal of Work and Organizational Psychology 20 (1): 60-67. doi: 10.1080/1359432X.2010.532869

Paul, A. K. and R. N. Anantharaman. 2003. "Impact of People Management Practices on Organizational Performance: Analysis of a Causal Model.” The International Journal of Human Resource Management 14 (7): 1246-1266. doi:10.1080/0958519032000145648

Podsakoff, P. M., S. B. MacKenzie, J. Y. Lee, and N.P. Podsakoff. 2003. “Common Method Biases in Behavioral Research: A Critical Review of the Literature and Recommended Remedies.” Journal of Applied Psychology 88 (5): 879-903. doi:10.1037/0021-9010.88.5.879

Pransky, G., S. Finkelstein, E. Berndt, M. Kyle, J. Mackell, and D. Tortorice. 2006. “Objective and Self-Report Work Performance Measures: A Comparative 
Analysis." International Journal of Productivity and Performance Management 55 (5): 390-399.

Preacher, K.J., and K. Kelley. 2011. “Effect Size Measures for Mediation Models: Quantitative Strategies for Communicating Indirect Effects.” Psychological Methods 16 (2): 93-115. doi:10.1037/a0022658

Purcell, J. 2014. "Disengaging from Engagement." Human Resource Management Journal 24 (3): 241-254. doi: 10.1111/1748-8583.12046

Rana, S. 2015. "High Involvement Work Practices and Employee Engagement.” Human Resource Development International online first: 1-9. doi:10.1080/13678868.2014. 1003698

Rees, C., K. Alfes and M. Gatenby. 2013. "Employee Voice and Engagement: Connections and Consequences.” The International Journal of Human Resource Management, 24 (14): 2780-2798. doi: 10.1080/09585192.2013.763843

Reio, T.G. and J. Sanders-Reio. 2011. "Thinking about Workplace Engagement: Does Supervisor and Coworker Incivility Really Matter?” Advances in Developing Human Resources 13 (4): 462-478. doi: 10.1177/1523422311430784

Rich, B. L., J. A. LePine, and E. R. Crawford. 2010. "Job Engagement: Antecedents and Effects on Job Performance." Academy of Management Journal 53 (3): 617-635. doi:10.5465/AMJ.2010.51468988

Rothbard, N. P. 2001. "Enriching or Depleting? The Dynamics of Engagement in Work and Family Roles.” Administrative Science Quarterly 46 (4): 655-684. doi: $10.2307 / 3094827$

Rurkkhum, S., and K.R. Bartlett. 2012. The Relationship between Employee Engagement and Organizational Citizenship Behaviour in Thailand. Human Resource Development International 15 (2): 157-174.doi: 10.1080/13678868.2012.664693 
Salanova, M., S. Agut, and J.M. Peiró. 2005. "Linking Organizational Resources and Work Engagement to Employee Performance and Customer Loyalty: The Mediation of Service Climate.” Journal of Applied Psychology 90 (6): 1217-1227. doi: $10.1037 / 00219010.90 .6 .1217$

Schaufeli, W.B. and A.B. Bakker. 2003. UWES: Utrecht Work Engagement Scale Preliminary Manual. Department of Psychology, Utrecht University, The Netherlands.

Schaufeli, W.B. and A.B. Bakker. 2010. "Defining and Measuring Work Engagement: Bringing Clarity to the Concept." In Work Engagement: A Handbook of Essential Theory and Research, edited by Arnold B. Bakker and Michael P. Leiter, 10-24. New York, NY: Psychology Press.

Schaufeli, W.B. and S. Salanova. 2008. "Enhancing Work Engagement through the Management of Human Resources.” In The Individual in the Changing Working Life, edited by Kathrina Näswall, Johnny Hellgren, and Magnus Sverke, 380-404. Cambridge: Cambridge University Press.

Schaufeli, W.B., M. Salanova, V. González-Romá, and A.B. Bakker. 2002. “The Measurement of Engagement and Burnout: A Two Sample Confirmatory Factor Analytic Approach.” Journal of Happiness Studies 3 (1): 71-92. doi: 10.1023/A:1015630930326

Schmidt, S. W. 2007. “The Relationship between Satisfaction with Workplace Training and Overall Job Satisfaction." Human Resource Development Quarterly 18 (4): 481498. doi: 10.1002/hrdq.1216

Seppälä, P., S. Mauno, T. Feldt, J. Hakanen, U. Kinnunen, A. Tolvanen, and W.B. Schaufeli. 2009. "The Construct Validity of the Utrecht Work Engagement Scale: 
Multisample and Longitudinal Evidence.” Journal of Happiness Studies 10 (4): 459481. doi: 10.1007/s10902-008-9100-y

Shuck, B. 2011. "Four Emerging Perspectives of Employee Engagement: An Integrative Literature Review." Human Resource Development Review 10 (3): 304-328. doi: $10.1177 / 1534484311410840$

Shuck, B. and T.S. Rocco. 2014. "Human Resource Development and Employee Engagement." In Employee Engagement in Theory and Practice, edited by Catherine Truss, Rick Delbridge, Kerstin Alfes, Amanda Shantz and Emma Soane, 116-130. London: Routledge.

Shuck, B., D. Twyford, T.G. Reio, and A. Shuck. 2014. "Human Resource Development Practices and Employee Engagement: Examining the Connection with Employee Turnover Intentions.” Human Resource Development Quarterly 25 (2): 239-270. doi: 10.1002/ hrdq. 21190

Soane, E., C. Truss, K. Alfes, A. Shantz, C. Rees, and M. Gatenby. 2013. "Development and Application of a New Measure of Employee Engagement: The ISA Engagement Scale." Human Resource Development International 15 (5): 529-547. doi: 10.1080/ 13678868.2012 .726542

Steiger, J. H. 1990. "Structural Model Evaluation and Modification: An Interval Estimation Approach.” Multivariate Behavioral Research 25 (2): 173-180. doi:10.1207/s15327906mbr2502_4

Sulea, C., D. Virga, L.P. Maricutoiu, W.B. Schaufeli, C. Zaborila Dumitru, and F.A Sava. 2012. "Work Engagement as Mediator between Job Characteristics and Positive and Negative Extra-Role Behaviors.” Career Development International 17 (3): 188-207. doi: 10.1108/13620431211241054 
Tonidandel, S., and J.M. LeBreton. 2011. "Relative Importance Analysis: A Useful Supplement to Regression Analysis.” Journal of Business and Psychology 26 (1): 1-9. doi:10.1007/s10869-0109204-3

Tonidandel, S., and J.M. LeBreton. 2014. "RWA Web: A Free, Comprehensive, Web Based, and User Friendly Tool for Relative Weight Analyses." Journal of Business and Psychology 30 (2): 207-216. doi: 10.1007/s10869-014-9351-z

Vance, R. J., R. C. MacCallum, M.D. Coovert, and J.W. Hedge. 1988. “Construct Validity of Multiple Job Performance Measures Using Confirmatory Factor Analysis.” Journal of Applied Psychology 73 (1): 74-80. doi:10.1037/00219010.73.1.74

Wefald, A.J., M.J. Mills, M.R. Smith, and R.G. Downey. 2012. “A Comparison of Three Job Engagement Measures: Examining their Factorial and Criterion-Related Validity. Applied Psychology: Health and Well-Being 4 (1): 67-90. doi: 10.1111/j.1758-0854.2011.01059.x 
Table 1. Comparing the conceptual foundations of personal role engagement and work engagement

\begin{tabular}{|c|c|c|c|c|c|}
\hline $\begin{array}{c}\text { Engagement } \\
\text { construct }\end{array}$ & Definition & Operationalisation & Measurement & Theoretical Framework & $\begin{array}{l}\text { The link to job } \\
\text { performance }\end{array}$ \\
\hline $\begin{array}{l}\text { Personal role } \\
\text { engagement }\end{array}$ & $\begin{array}{l}\text { Engagement is the act of } \\
\text { "harnessing...organization } \\
\text { members' [preferred] selves } \\
\text { to their work roles" (Kahn } \\
\text { 1990, 694). } \\
\text { A psychological state that } \\
\text { alternate between pure forms } \\
\text { of engagement (i.e., } \\
\text { employment of self) and } \\
\text { disengagement (i.e., } \\
\text { withdrawal of self) along a } \\
\text { continuum (Kahn 1990). }\end{array}$ & $\begin{array}{l}\text { An engaged employee will } \\
\text { "employ and express themselves } \\
\text { physically, cognitively and } \\
\text { emotionally during role } \\
\text { performances" (Kahn 1990, 694). } \\
\text { "Engagement reflects...a } \\
\text { common cause of the investment } \\
\text { of the various energies" (Rich et } \\
\text { al. 2010, 619). } \\
\text { Engagement involves activation, } \\
\text { positive affect, and a focused role } \\
\text { that allows the individual to } \\
\text { connect with the wider work } \\
\text { context (Soane et al. 2013). }\end{array}$ & $\begin{array}{l}\text { Soane et al's (2013) ISA scale } \\
\text { Intellectual engagement } \\
\text { I focus hard on my work } \\
\text { I concentrate on my work } \\
\text { I pay a lot of attention to my work } \\
\text { Social engagement } \\
\text { I share the same work values as my } \\
\text { colleagues } \\
\text { I share the same work goals as my } \\
\text { colleagues } \\
\text { I share the same work attitudes as my } \\
\text { colleagues } \\
\text { Affective engagement } \\
\text { I am enthusiastic in my work } \\
\text { I feel positive about my work } \\
\text { I feel energetic in my work }\end{array}$ & $\begin{array}{l}\text { Kahn's (1990) psychological } \\
\text { conditions of meaningfulness, } \\
\text { availability and safety. These } \\
\text { conditions mirror a relational } \\
\text { psychological contract and act to } \\
\text { mediate the relationship between } \\
\text { the work context (e.g., job } \\
\text { characteristics, emotional } \\
\text { resources, supervisory relations) } \\
\text { and engagement. }\end{array}$ & $\begin{array}{l}\text { Engagement } \\
\text { focuses the } \\
\text { investment of } \\
\text { personal energies } \\
\text { and aspects of the } \\
\text { self into the work } \\
\text { role and so 'full } \\
\text { and active' } \\
\text { performance in the } \\
\text { job will result } \\
\text { (Rich et al. 2010). }\end{array}$ \\
\hline $\begin{array}{l}\text { Work } \\
\text { engagement }\end{array}$ & $\begin{array}{l}\text { "A positive, fulfilling, work- } \\
\text { related state of mind" } \\
\text { (Schaufeli et al. 2002, 74). } \\
\text { A psychological state that is } \\
\text { "persistent and } \\
\text { pervasive...(and) not focused } \\
\text { on any particular object, } \\
\text { event, individual, or } \\
\text { behavior" (Schaufeli et al. } \\
\text { 2002, 74). }\end{array}$ & $\begin{array}{l}\text { An engaged employee has a } \\
\text { strong sense of vigor (i.e., energy } \\
\text { and resilience), dedication (i.e., } \\
\text { involvement and enthusiasm), and } \\
\text { absorption (i.e., pleasant state of } \\
\text { immersion) in work activities } \\
\text { (Schaufeli et al. 2002) }\end{array}$ & $\begin{array}{l}\text { Schaufeli et al's (2002) UWES-9 } \\
\text { Vigor } \\
\text { At my work, I feel bursting with energy } \\
\text { At my job, I feel strong and vigorous } \\
\text { When I get up in the morning, I feel like } \\
\text { going to work } \\
\text { Dedication } \\
\text { I am enthusiastic about my job } \\
\text { My job inspires me } \\
\text { I am proud on the work that I do } \\
\text { Absorption } \\
\text { I feel happy when I am working intensely } \\
\text { I am immersed in my work } \\
\text { I get carried away when I'm working }\end{array}$ & $\begin{array}{l}\text { Job resources (e.g., autonomy, } \\
\text { social support, performance } \\
\text { feedback) and personal resources } \\
\text { (e.g., optimism, self-efficacy, } \\
\text { resilience) trigger a motivational } \\
\text { process that leads to engagement. } \\
\text { Job demands (e.g., work pressure, } \\
\text { emotional demands, physical } \\
\text { demands) strengthen the } \\
\text { relationship between job/personal } \\
\text { resources and } \\
\text { engagement.(Bakker and } \\
\text { Demerouti 2008) }\end{array}$ & $\begin{array}{l}\text { Engagement } \\
\text { directs an } \\
\text { individual's efforts } \\
\text { towards the } \\
\text { completion of } \\
\text { work tasks and } \\
\text { activities (Parker } \\
\text { and Griffin 2011). }\end{array}$ \\
\hline
\end{tabular}


Table 2. Means, standard deviations, and correlations of the variables

\begin{tabular}{|c|c|c|c|c|c|c|c|c|c|c|c|c|}
\hline Variable & Mean & SD & 1 & 2 & 3 & 4 & 5 & 6 & 7 & 8 & 9 & 10 \\
\hline 1. Gender & - & - & - & & & & & & & & & \\
\hline 2. Age & 41.45 & 11.69 & -.29 & - & & & & & & & & \\
\hline 3. Tenure & 9.96 & 8.94 & -.25 & .51 & - & & & & & & & \\
\hline 4. Management responsibility & - & - & .03 & .02 & -.07 & - & & & & & & \\
\hline 5. Training perceptions & 3.37 & 0.88 & .09 & -.01 & .02 & -.19 & $(.90)$ & & & & & \\
\hline 6. Work engagement & 3.13 & 0.80 & .03 & .04 & .06 & -.28 & .49 & $(.94)$ & & & & \\
\hline 7. Personal role engagement & 3.59 & 0.67 & .06 & .05 & .06 & -.14 & .59 & .69 & $(.91)$ & & & \\
\hline 8. Task proficiency & 3.97 & 0.94 & -.06 & .28 & .12 & .14 & .14 & .23 & .39 & $(.95)$ & & \\
\hline 9. Task adaptability & 3.53 & 0.90 & .06 & .12 & .04 & -.08 & .24 & .33 & .44 & .66 & $(.82)$ & \\
\hline 10. Task proactivity & 3.17 & 1.05 & .10 & -.10 & -.07 & -.18 & .27 & .42 & .38 & .31 & .65 & $(.94)$ \\
\hline
\end{tabular}

Note: Cronbach's alpha reliability scores given in parentheses. $\mathrm{r}+/-.10 \mathrm{p}=.05 ; \mathrm{r}+/-.14 \mathrm{p}=.001 ; \mathrm{r}+/-.18 \mathrm{p}=.001$ 
Table 3. Confirmatory factor analyses of the engagement constructs

\begin{tabular}{|llllllrr|}
\hline & $\chi^{2}(\mathrm{df})$ & $\Delta \chi^{2}(\mathrm{df})$ & AIC & \multicolumn{1}{l}{ BIC } & RMSEA & CFI & SRMR \\
\hline 1 factor alternative & $1941.00^{* * *}(135)$ & & 11425.52 & 11626.24 & 0.21 & 0.64 & 0.12 \\
2 factor alternative & $1479.30 * * *(134)$ & $461.70 * * *(1)$ & 10965.81 & 11170.25 & 0.19 & 0.73 & 0.11 \\
3 factor alternative & $1413.66 * * *(132)$ & $65.64 * * *(2)$ & 10904.18 & 11116.05 & 0.18 & 0.75 & 0.10 \\
4 factor alternative & $1127.91 * * *(129)$ & $285.75 * * *(3)$ & 10624.42 & 10847.45 & 0.16 & 0.80 & 0.09 \\
5 factor alternative & $708.92 * * *(125)$ & $418.99 * * *(4)$ & 10213.44 & 10451.33 & 0.12 & 0.88 & 0.06 \\
6 factor & $444.95 * * *(120)$ & $263.97 * *(5)$ & 9959.47 & 10215.94. & 0.09 & 0.94 & 0.05 \\
\hline
\end{tabular}

Note: 2 factor (ISA-Intellectual, UWES-Absorption ISA-Affective, UWES-Dedication, UWES-Vigor)/(ISA-Social); 3 factor (ISA-

Intellectual,UWES-Absorption,ISA-Affective,UWES-Dedication)/(UWES-Vigor)/(ISA-Social); 4 factor (ISA-Intellectual,UWES-

Absorption)/(ISA-Affective,UWES-Dedication)/(UWES-Vigor)/(ISA-Social); 5 factor (ISA-Intellectual)/(UWES-Absorption)/(ISAAffective,UWES-Dedication)/(UWES-Vigor)/(ISA-Social); 6 factor (ISA-Intellectual)/(UWES-Absorption)/(ISA-Affective)/UWES-

Dedication $) /($ UWES-Vigor $) /($ ISA-Social $)$

$* p<.05, * * p<.01, * * * p<.001$ 
Table 4. Confirmatory factor analyses of all latent variables

\begin{tabular}{|llllllll|}
\hline & $\chi^{2}(\mathrm{df})$ & $\Delta \chi^{2}(\mathrm{df})$ & AIC & BIC & RMSEA & CFI & SRMR \\
\hline 1 factor alternative & $3128.00 * * *(152)$ & & 14104.13 & 14316.00 & 0.25 & 0.40 & 0.17 \\
2 factor alternative & $2073.49 * * *(151)$ & $1054.51 * * *(1)$ & 13051.63 & 13267.21 & 0.21 & 0.61 & 0.16 \\
3 factor alternative & $1630.39 * * *(149)$ & $443.10 * * *(2)$ & 12612.52 & 12835.54 & 0.18 & 0.70 & 0.16 \\
4 factor alternative & $972.60 * * *(146)$ & $657.79 * * *(3)$ & 11960.73 & 12194.91 & 0.14 & 0.83 & 0.12 \\
5 factor alternative & $636.14 * * *(142)$ & $336.46 * * *(4)$ & 11632.27 & 11881.31 & 0.11 & 0.90 & 0.09 \\
6 factor & $551.16 * * *(137)$ & $84.98 * * *(5)$ & 11557.29 & 11824.92 & 0.10 & 0.92 & 0.08 \\
\hline
\end{tabular}

Note:2 factor (training perceptions, work engagement, personal role engagement)/(task proficiency, task adaptability, task

proactivity); 3 factor (training perceptions)/(work engagement, personal role engagement)/( task proficiency, task adaptability,

task proactivity); 4 factor (training perceptions)/(work engagement, personal role engagement)/( task proficiency)/(task

adaptability, task proactivity); 5 factor (training perceptions)/(work engagement, personal role engagement)/( task

proficiency)/(task adaptability)/( task proactivity); 6 factor factor (training perceptions)/(work engagement)/(personal role engagement)/( task proficiency)/(task adaptability)/( task proactivity)

$* p<.05, * * p<.01, * * * p<.001$ 
Table 5. Multiple regressions and relative weight analyses for predicting work role behaviours

\begin{tabular}{|c|c|c|c|c|c|c|c|c|c|c|c|c|c|c|c|c|c|c|}
\hline & \multicolumn{6}{|c|}{ Predicting task proficiency } & \multicolumn{6}{|c|}{ Predicting task adaptability } & \multicolumn{6}{|c|}{ Predicting task proactivity } \\
\hline & Step 1 & Step 2 & $\begin{array}{l}\text { Relative } \\
\text { Weight } \\
(r w)\end{array}$ & $\begin{array}{l}\text { Rescaled } \\
r w\end{array}$ & $\begin{array}{l}\text { Lower } \\
\text { Bound } \\
r w\end{array}$ & $\begin{array}{l}\text { Upper } \\
\text { Bound } \\
r w\end{array}$ & Step 1 & Step 2 & $\begin{array}{l}\text { Relative } \\
\text { Weight } \\
(r w)\end{array}$ & $\begin{array}{l}\text { Rescaled } \\
r w\end{array}$ & $\begin{array}{l}\text { Lower } \\
\text { Bound } \\
r w\end{array}$ & $\begin{array}{l}\text { Upper } \\
\text { Bound } \\
r w\end{array}$ & Step 1 & Step 2 & $\begin{array}{l}\text { Relative } \\
\text { Weight } \\
(r w)\end{array}$ & $\begin{array}{l}\text { Rescaled } \\
r w\end{array}$ & $\begin{array}{l}\text { Lower } \\
\text { Bound } \\
r w\end{array}$ & $\begin{array}{l}\text { Upper } \\
\text { Bound } \\
r w\end{array}$ \\
\hline Gender & .00 & -.02 & .00 & 0.1 & -.03 & .01 & .08 & .06 & .01 & 1.7 & -.01 & .02 & .06 & .05 & .01 & 2.3 & -.01 & .03 \\
\hline Age & $.27 * * *$ & $.26 * * *$ & .06 & 23.8 & .02 & .12 & $.15^{*}$ & $.14 *$ & .01 & 6.6 & -.01 & .05 & -.08 & -.08 & .01 & 3.4 & -.01 & .03 \\
\hline Tenure & -.02 & -.03 & .01 & 2.6 & -.02 & .02 & -.04 & -.04 & .00 & 0.5 & -.03 & .01 & -.05 & -.05 & .00 & 1.8 & -.01 & .03 \\
\hline $\begin{array}{l}\text { Management } \\
\text { responsibility }\end{array}$ & $.21 * * *$ & $.19 * * *$ & .03 & 11.8 & -.01 & .08 & .01 & -.01 & .00 & 1.0 & -.02 & .02 & -.07 & -.08 & .02 & 8.12 & -.01 & .05 \\
\hline $\begin{array}{l}\text { Work } \\
\text { engagement }\end{array}$ & $.28 * * *$ & -.01 & .03 & 12.7 & -.01 & .06 & $.33 * * *$ & .05 & .05 & 25.7 & .02 & .10 & $.41 * * *$ & $.27 * * *$ & .10 & 47.2 & .05 & .17 \\
\hline $\begin{array}{l}\text { Personal role } \\
\text { engagement }\end{array}$ & & $.41 * * *$ & .12 & 48.2 & .05 & .20 & & $.39 * * *$ & .14 & 64.4 & .08 & .20 & & $.19 * *$ & .08 & 37.2 & .03 & .13 \\
\hline $\mathrm{R}^{2}\left(\Delta \mathrm{R}^{2}\right)$ & $.17 * * *$ & $\begin{array}{l}.25 * * * \\
(.09 * * *)\end{array}$ & & & & & $.13 * * *$ & $\begin{array}{l}.21 * * * \\
.08 * * *)\end{array}$ & & & & & $.20 * * *$ & $\begin{array}{l}.22 * * * \\
(.02 * *)\end{array}$ & & & & \\
\hline
\end{tabular}

$* p<.05, * * p<.01, * * * p<.001$ 
Table 6. Multiple regression analyses for the effects of training perceptions on work role behaviours via work engagement and personal role engagement

\begin{tabular}{|c|c|c|c|c|c|c|c|c|c|c|c|}
\hline \multirow[b]{2}{*}{ Predictor } & \multirow{2}{*}{$\begin{array}{l}\text { Predicting } \\
\text { work } \\
\text { engagement }\end{array}$} & \multirow{2}{*}{$\begin{array}{l}\text { Predicting } \\
\text { personal role } \\
\text { engagement }\end{array}$} & \multicolumn{3}{|c|}{ Predicting task proficiency } & \multicolumn{3}{|c|}{ Predicting task adaptability } & \multicolumn{3}{|c|}{ Predicting task proactivity } \\
\hline & & & Step 1 & Step 2a & Step $2 b$ & Step 1 & Step 2a & Step $2 b$ & Step 1 & Step $2 \mathrm{a}$ & Step $2 b$ \\
\hline Gender & .00 & .02 & $\begin{array}{l}-.01 \\
\end{array}$ & -.01 & -.02 & .07 & .07 & .06 & .05 & .05 & .04 \\
\hline Age & .02 & .08 & $.24 * * *$ & $.24 * * *$ & $.20 * * *$ & .11 & .10 & .08 & -.11 & -.11 & $-.13^{*}$ \\
\hline $\begin{array}{l}\text { Management } \\
\text { responsibility }\end{array}$ & $-.19 * * *$ & -.03 & $.16^{* *}$ & $.21 * * *$ & $.18 * * *$ & -.02 & .01 & -.01 & $-.13 *$ & -.07 & $-.13^{*}$ \\
\hline Tenure & .02 & .01 & .01 & .00 & -.01 & .01 & .01 & .01 & -.01 & -.01 & -.01 \\
\hline Training perceptions & $.47 * * *$ & $.59 * * *$ & $.17 * *$ & .06 & -.12 & $.23 * * *$ & $.16^{*}$ & .01 & $.24 * * *$ & .09 & .05 \\
\hline Work engagement & & & & $.23 * * *$ & & & $.16^{*}$ & & & $.32 * * *$ & \\
\hline $\begin{array}{l}\text { Personal role } \\
\text { engagement }\end{array}$ & & & & & $.49 * * *$ & & & $.38 * * *$ & & & $.32 * * *$ \\
\hline & $29 * * *$ & $.37 * * *$ & $.10 * * *$ & $.14 * * *$ & $.25 * * *$ & $.07 * * *$ & $.09 * * *$ & $.16 * * *$ & $.11 * * *$ & $.18 * * *$ & $.17 * * *$ \\
\hline $\mathrm{R}^{2}\left(\Delta \mathrm{R}^{2}\right)$ & & & & $(.04 * *)$ & $\left(.15^{* * *}\right)$ & & $(.02 *)$ & $(.12 * * *)$ & & $(.07 * * *)$ & $\left(.06^{* * *}\right)$ \\
\hline
\end{tabular}

Note: Standard betas are given.. $* p<.05, * * p<.01, * * * p<.001$ 
Table 7. PROCESS output results for the indirect effect of training perceptions on work role behaviours via work engagement and personal role engagement

\begin{tabular}{|c|c|c|c|c|c|c|c|c|}
\hline & \multicolumn{4}{|c|}{ Work engagement as mediator } & \multicolumn{4}{|c|}{ Personal role engagement as mediator } \\
\hline & Est. (SE) & Lower Bound & Upper Bound & Effect Size & Est. (SE) & Lower Bound & Upper Bound & Effect Size \\
\hline Training perceptions - Task proficiency & $.11(.03)$ & .05 & .19 & .11 & $.30(.04)$ & .22 & .40 & .29 \\
\hline Training perceptions - Task adaptability & $.08(.03)$ & .01 & .15 & .08 & $.22(.05)$ & .12 & .33 & .22 \\
\hline Training perceptions - Task proactivity & $.18(.04)$ & .10 & .27 & .15 & $.22(.07)$ & .09 &. .35 & .19 \\
\hline
\end{tabular}

Note: Effect size is the completely standardised indirect effect as outlined by Preacher and Kelley (2011). 